\title{
MicroRNA-1271-5p alleviates the malignant development of hepatitis B virus-mediated liver cancer via binding to AQP5
}

\author{
ZHIGANG LI ${ }^{1}$, LIN MA ${ }^{2}$, LINGLING DI ${ }^{3}$ and XUTAO LIN ${ }^{4}$ \\ ${ }^{1}$ Department of Infectious Diseases, The Second Affiliated Hospital of Shandong First Medical University, Tai'an, \\ Shandong 271000; ${ }^{2}$ Department of Pharmacy, Liaocheng People's Hospital, Liaocheng, Shandong 252000; \\ ${ }^{3}$ Department of General Surgery, Central Hospital of Xinwen Mining Group Co., Ltd., Tai'an, Shandong 271000; \\ ${ }^{4}$ Department of Hepatobiliary Surgery, Binzhou Medical University Hospital, Binzhou, Shandong 256600, P.R. China
}

Received September 26, 2019; Accepted October 6, 2020

DOI: $10.3892 / \mathrm{mmr} .2021 .12025$

\begin{abstract}
Hepatitis B virus (HBV) is a leading cause of liver-related cancer. Progress has been made on the study of microRNA (miRNA or miR) function in HBV-related liver cancer. Hence, the objective of the present study was to determine the role and functional mechanism of miR-1271-5p in HBV-associated liver cancer. miR-1271-5p and aquaporin 5 (AQP5) expression at the mRNA level were measured by reverse transcription-quantitative PCR (RT-qPCR). The levels of hepatitis B e-antigen ( $\mathrm{HBeAg}$ ), hepatitis B surface antigen (HBsAg) and HBV DNA were assessed by ELISA or qPCR. Cell viability, apoptosis, migration and invasion were detected by Cell Counting Kit-8, flow cytometry or Transwell assay. The interaction of miR-1271-5p and AQP5 was predicted by TargetScan, and verified by Dual-luciferase reporter assay and RNA binding protein immunoprecipitation assay. The protein levels of AQP5, Bax, Bcl-2, cleaved-caspase-3 and proliferating cell nuclear antigen were quantified by western blot analysis. Nude mouse tumorigenicity assay was conducted to examine the role of miR-1271-5p in vivo. miR-1271-5p was downregulated, while AQP5 was upregulated in HBV-related liver cancer cells and tissues. Overexpression of miR-1271-5p or AQP5 knockdown inhibited the levels of $\mathrm{HBeAg}, \mathrm{HBsAg}$ and HBV DNA, blocked cell viability, migration and invasion, and induced apoptosis. AQP5 was confirmed to be a direct target of miR-1271-5p, and miR-1271-5p exerted its role through targeting AQP5. Overexpression of miR-1271-5p impeded tumor growth in vivo by weakening the expression of AQP5. In conclusion, miR-1271-5p blocked the progression of HBV-induced liver cancer by competitively targeting AQP5.
\end{abstract}

Correspondence to: Mr. Xutao Lin, Department of Hepatobiliary Surgery, Binzhou Medical University Hospital, 661 Huangheer Road, Binzhou, Shandong 256600, P.R. China

E-mail: byfybgs@bz.shandong.cn

Key words: miR-1271-5p, aquaporins 5, hepatitis B virus, liver cancer

\section{Introduction}

Currently, the occurrence of liver cancer, particularly hepatocellular carcinoma (HCC), is increasing worldwide (1), and liver cancer is the third most common cause of cancer-related mortality (2). Compared with that of the general population, chronic hepatitis B virus (HBV) carriers have a higher risk of contracting $\mathrm{HCC}$, and $\mathrm{HBV}$ is the most direct cause of $\mathrm{HCC}(3)$. The HBV DNA molecule, which is a circular double-stranded DNA containing part of a single-stranded region, transforms into covalently closed circular (ccc)DNA during its life cycle (4). As a marker of HBV infection, hepatitis B e-antigen ( $\mathrm{HBeAg}$ ) positivity is associated with high viral loads, which further leads to high expression levels of hepatitis B surface antigen (HBsAg) (5). Therefore, it is urgent to investigate novel biomarkers for the development and metastasis of HBV-related liver cancer from the influence of antigen activity and DNA replication.

MicroRNAs (miRNAs or miRs), a type of small, non-coding RNA of 18 25 nucleotides in length, mainly regulate mRNA expression by modulating their translation and degradation via combining with the $3^{\prime}$ untranslated region (3' UTR) of the target mRNA (6). miRNAs partly involved in the progress of HBV-related HCC have attracted much attention. For example, miR-384 expression is reduced in HBV-induced HCC, and its dysregulation has acute effects on proliferation, metastasis and lipogenesis (7). miR-204 and miR-1236 are downregulated in HBV-producing cells, and their overexpression can inhibit HBV DNA replication (8). miR-106b, which was observed to be upregulated in patients with HCC by miRNA array analysis, is associated with poor prognosis of patients with HBV-associated HCC (9). These data indicate that different miRNAs have variable regulatory efficacy in HBV-HCC. The role of miR-1271-5p is partly reported in HCC (10). However, its role in HBV-associated liver cancer remains to be elucidated.

Aquaporins (AQPs) are transport channels that promote water permeation through cell membranes (11). Water channels serve vital roles in numerous biological processes, particularly the maintenance of water homeostasis (12). AQP5, a member of the AQP family, is a primary water-selective channel. Emerging data suggest that AQP5 expression may 
be involved in the growth and development of a number of systemic malignancies. For instance, AQP5 is overexpressed in squamous cell carcinoma (12), non-small cell lung (13), lung (14) and breast cancer (15). Thus, AQP5 may function as an oncogene in numerous types of cancer. However, studies on AQP5 expression and function in HBV-associated liver cancer remain limited.

In the present study, the abundance of miR-1271-5p and AQP5 was measured in HBV-related liver cancer tissues and cells. The role of miR-1271-5p was analyzed according to the levels of HBeAg and HBsAg, HBV DNA replication, cell viability, apoptosis, migration and invasion in vitro, as well as tumor growth in vivo. The interaction between miR-1271-5p and AQP5 was verified, thus providing a potential regulatory mechanism of miR-1271-5p.

\section{Materials and methods}

Specimens. The present study was approved by the Ethics Committee of The Second Affiliated Hospital of Shandong First Medical University (Tai'an, China). A total of 32 HBV-induced HCC tissues and paired adjacent healthy tissues were collected from The Second Affiliated Hospital of Shandong First Medical University from October 2015 to February 2018. All samples were placed immediately in liquid nitrogen and then stored at $-80^{\circ} \mathrm{C}$ until use. All patients (including 20 males and 12 females, aged 36-62 years) had signed the informed consent form before tissue resection.

Cell lines and culture. The hepatoblastoma cell line HepG2.2.15 and the HCC cell line Huh7 were purchased from the BeNa Culture Collection. The cells were cultured in Dulbecco's modified Eagle's medium (DMEM) supplemented with $10 \%$ fetal bovine serum (FBS), $100 \mu \mathrm{g} / \mathrm{ml}$ streptomycin and $100 \mathrm{U} / \mathrm{ml}$ penicillin (all from Gibco; Thermo Fisher Scientific, Inc.) at $37^{\circ} \mathrm{C}$ with $5 \% \mathrm{CO}_{2}$.

Cell transfection. To mimic HBV infection, a plasmid with 1.3 mer HBV genomic DNA (pcDNA3.1-1.3 mer) was transfected into Huh7 cells using FuGENE ${ }^{\circledR}$ HD Transfection reagent (Promega Corporation), thus generating the HBV-HCC cell line Huh7-1.3. miR-1271-5p mimic (miR-1271-5p; $40 \mathrm{nM}$; 5'-CUUGGCACCUAGCAAGCACUCA-3') or miR-1271-5p inhibition (anti-miR-1271-5p; 60 nM; 5'-UGAGUGCUU GCUAGGUGCCAAG-3') and their corresponding control miR-negative control (NC) or anti-miR-NC were purchased from Guangzhou RiboBio Co., Ltd. The small interference (si)RNA against AQP5 (si-AQP5; $2.5 \mu \mathrm{g} ; 5$ '-GACAGACUG GUUCAUUGAAUG-3'), the scrambled siRNA (Scramble; $2.5 \mu \mathrm{g}$ ), pcDNA3.1-AQP5 (AQP5; $1 \mu \mathrm{g}$ ) and pcDNA3.1 empty vector (vector; $1 \mu \mathrm{g}$ ) were all obtained from Shanghai GenePharma Co., Ltd. These transfection assays were conducted using Lipofectamine ${ }^{\circledR} 2000$ (Invitrogen; Thermo Fisher Scientific, Inc.) according to the manufacturer's protocol. Blank transfection served as the control. The experiments described below were performed at $48 \mathrm{~h}$ after transfection.

Reverse transcription-quantitative PCR (RT-qPCR). Total RNA was isolated from tissues or cells $\left(5 \times 10^{6}\right.$ cells) using
TRIzol $^{\circledR}$ reagent (Thermo Fisher Scientific, Inc.) according to the manufacturer's protocol. cDNA was synthesized using miRNA cDNA Synthesis kit (Applied Biological Materials Inc.) for miR-1271-5p or PrimeScript RT Reagent kit (Takara Bio, Inc.) for AQP5 according to the manufacturer's protocol using the following reaction conditions: $42^{\circ} \mathrm{C}$ for $15 \mathrm{~min}$ and $85^{\circ} \mathrm{C}$ for $5 \mathrm{~min}$. qPCR was performed using TB Green Premix Ex Taq II (Takara Bio, Inc.) on an ABI 7900 (Applied Biosystems; Thermo Fisher Scientific, Inc.) according to the manufacturer's protocol. The thermocycling conditions were as follows: Denaturation at $95^{\circ} \mathrm{C}$ for $30 \mathrm{sec}, 95^{\circ} \mathrm{C}$ for $5 \mathrm{sec}$ and $60^{\circ} \mathrm{C}$ for $1 \mathrm{~min}$ for a total of 40 cycles. GAPDH or small nuclear RNA U6 acted as an internal reference for AQP5 or miR-1271-5p, respectively. The relative expression was calculated using the $2^{-\Delta \Delta \mathrm{Cq}}$ method (16). The primers used were: miR-1271-5p, forward, 5'-CTTGGCACCTAGCAAGCACTC A-3' and reverse, 5'-GCGAGCACAGAATTAATACGAC-3'; AQP5, forward, 5'-GCCATCCTCTATTTCTACCTGC-3' and reverse, 5'-GCTTCAAACTCTTCGTCTTCC-3'; GAPDH, forward, 5'-CATCACCATCTTCCAGGAGCG-3' and reverse, 5'-TGACCTTGCCCACAGCCTTG-3'; and U6, forward, 5'-AGAGCCTGTGGTGTCCG-3' and reverse, 5'-CATCTT CAAAGCACTTCCCT-3'.

ELISA. ELISA was employed to analyze the levels of HBsAg and HBeAg using ELISA kits (cat. nos. INS1030201 and INS1030203; Huangshi Irons Biotechnology Co., Ltd.) according to the manufacturer's protocols. Antibodies against HBsAg (1:2,000; cat. no. ab9193; Abcam) and HBeAg (1:2,000; cat. no. ab91273; Abcam) were used for ELISA. The inhibitory rate was analyzed according to the formula: Inhibitory rate $(\%)=\left(\mathrm{C}_{\text {control }}-\mathrm{C}_{\text {tested }}\right) / \mathrm{C}_{\text {control }} \mathrm{x} 100 \%$, where $\mathrm{C}$ is the concentration.

Detection of HBV DNA level. Viral DNA was isolated from transfected HepG2.2.15 and Huh7-1.3 cells using QIAamp DNA Mini kits (Qiagen $\mathrm{GmbH}$ ) according to the manufacturer's protocols. An HBV PCR Fluorescence Quantitative Detection kit (Hangzhou Bioer Co., Ltd.) was used for quantitative detection of HBV DNA by quantitative PCR in accordance with the manufacturer's protocols. The average $\mathrm{Cq}$ values were used to ascertain the level of HBV DNA. The calculation of the inhibitory rate was performed as aforementioned.

Cell Counting Kit-8 (CCK-8) assay. To evaluate cell viability, a CCK-8 reagent (Beyotime Institute of Biotechnology) was used in accordance with the manufacturer's protocols. In brief, transfected Huh7-1.3 and HepG2.2.15 cells were seeded in a 96-well plate (Corning Inc. $2 \times 10^{3}$ cells/well) for 24,48 and $72 \mathrm{~h}$. Cells at different stages were collected and treated with the CCK-8 solution for another $2 \mathrm{~h}$ at room temperature. The absorbance at $450 \mathrm{~nm}$ was measured using a microplate reader (Thermo Fisher Scientific, Inc.) at room temperature.

Flow cytometry assay. For apoptosis, an Annexin V-FITC/PI kit (BD Pharmingen; BD Biosciences) was used to perform the flow cytometry assay according to the manufacturer's protocol. Transfected cells $\left(5 \times 10^{4}\right)$ were digested with $0.25 \%$ trypsin, washed with PBS and fixed in $70 \%$ cold ethanol at $4^{\circ} \mathrm{C}$ for $12 \mathrm{~h}$. Upon washing with PBS, the cells were stained 
with FITC-Annexin V and PI for 30 min in the dark. Finally, fluorescence was recorded with a CytoFLEX flow cytometer (Beckman Coulter, Inc.), and the apoptotic cells were analyzed using Kaluza software (version 2.1; Beckman Coulter, Inc.). The apoptotic cells was calculated as the percentage of late (Annexin V-FITC) $)^{+} / \mathrm{PI}^{+}$and early apoptotic cells (Annexin V-FITC) ${ }^{+} / \mathrm{PI}^{-}$.

Western blot analysis. RIPA lysis solution (Beyotime Institute of Biotechnology) was used to extract total proteins from cells or tumor tissue. After quantifying the concentration of the lysates using BCA Protein Assay kit (Beyotime Institute of Biotechnology), the proteins $(40 \mu \mathrm{g})$ were separated by $12 \%$ SDS-PAGE and transferred onto PVDF membranes (Bio-Rad Laboratories, Inc.) on ice. Subsequently, the membranes were blocked with $5 \%$ skimmed milk at room temperature for $1 \mathrm{~h}$ and then incubated with primary antibodies against Bax (1:1,000; cat. no. ab182734), Bcl-2 (1:1,000; cat. no. ab194583), cleaved-caspase-3 (1:500; cat. no. ab49822), AQP5 (1:2,000; cat. no. ab92320), proliferating cell nuclear antigen (PCNA; 1:2,000; cat. no. ab29) and GAPDH (1:10,000; cat. no. ab8245; all from Abcam) overnight at $4^{\circ} \mathrm{C}$. On the following day, the membranes were incubated with a secondary antibody conjugated to horseradish peroxidase (1:5,000; cat. nos. ab205718 and ab205719; Abcam) at room temperature for $2 \mathrm{~h}$ after washing with TBS. The blots were visualized by an enhanced chemiluminescence kit (Beyotime Institute of Biotechnology), and images were captured for densitometry using ImageJ software (version 1.46; National Institutes of Health).

Transwell assay. A part of the upper surface of Transwell chambers $(8 \mu \mathrm{m})$ was treated with Matrigel (Corning Inc.) at $4^{\circ} \mathrm{C}$ overnight before the experiment. Transfected HepG2.2.15 and Huh7-1.3 cells were collected by centrifugation $\left(326 \mathrm{x} \mathrm{g} ; 5 \mathrm{~min} ; 4^{\circ} \mathrm{C}\right)$ and resuspended in serum-free DMEM. The cells $\left(5 \times 10^{4}\right)$ were transferred to the top of Transwell chambers without Matrigel for migration assays or to the top of Transwell chambers containing Matrigel for invasion assays. The bottom of the Transwell chambers was filled with DMEM containing 10\% FBS. After incubating for $24 \mathrm{~h}$, the migrated or invaded cells through the membrane were fixed with $95 \%$ ethanol for 15 min and stained with $0.1 \%$ crystal violet for $20 \mathrm{~min}$ at room temperature. Cells passing through the basement membranes were counted using a Leica DC 300F light microscope (magnification, x100; Leica Microsystems GmbH).

Prediction of target genes. The online software TargetScan Human 7.2 (targetscan.org/vert_72/) was used to predict the possible target genes of miR-1271-5p and to analyze the binding sites between them.

Dual-luciferase reporter assay. The luciferase reporter vector PGL3-basic (Promega Corporation) was employed to verify the association between miR-1271-5p and AQP5. Specifically, PGL3-AQP5 wild-type (wt) fusion vector containing AQP5 3' UTR wt sequence and PGL-AQP5 mutant (mut) fusion vector containing AQP5 3' UTR mut sequence were assembled and transfected into HepG2.2.15 and Huh7-1.3 cells together with miR-1271-5p, miR-NC, anti-miR-1271-5p or anti-miR-NC using Lipofectamine ${ }^{\circledR}$ 2000 (Invitrogen; Thermo Fisher Scientific, Inc.). After $48 \mathrm{~h}$, the luciferase activity was estimated using the Dual-Luciferase Reporter Assay System (Promega Corporation), according to the manufacturer's protocol. Relative luciferase activity was assessed by comparison with Renilla luciferase activity.

RNA binding protein immunoprecipitation (RIP) assay. HepG2.2.15 and Huh7-1.3 cells $\left(1 \times 10^{5}\right)$ transfected with miR-1271-5p or miR-NC were collected and lysed with RIP lysis buffer containing protease inhibitor and RNase inhibitor from an EZ-Magna RIP kit (EMD Millipore). The above reactant was incubated with magnetic beads combined with an antibody against Ago 2 or with an $\lg \mathrm{G}$ control for $6 \mathrm{~h}$ at $4^{\circ} \mathrm{C}$. Finally, the reaction products were purified and analyzed by RT-qPCR to monitor the enrichment of AQP5.

In vivo experiments. The animal experiments were approved by the Institutional Animal Care and Use Committee of The Second Affiliated Hospital of Shandong First Medical University. In brief, $12 \mathrm{BALB} / \mathrm{c}$ nude mice (male, 6-week old, mean weight $14.6 \mathrm{~g}$ ) purchased from Shanghai SLAC Laboratory Animal Co., Ltd. were divided into 2 groups $(n=6)$ and housed in pathogen-free conditions (temperature, $23^{\circ} \mathrm{C}$; humidity, 55\%; light/dark cycle, 12/12h). The right flank of the back was subcutaneously injected with HepG2.2.15 cells $\left(5 \times 10^{6}\right)$ transfected with lentiviral vectors with miR-1271-5p or miR-NC. Tumor volumes (length $\mathrm{x}$ width ${ }^{2} \mathrm{x} 0.5$ ) were recorded every 7 days using a vernier caliper. Tumor weight was measured for 5 weeks until the mice were sacrificed via cervical dislocation. The mice were sacrificed when $>20 \%$ body weight was lost. The excisional tumor tissues were used for further analyses, including RT-qPCR and western blotting as aforementioned.

Statistical analysis. All tests were independently conducted $\geq 3$ times. Experimental data are presented as the mean \pm standard deviation, and were analyzed by SPSS 17.0 (SPSS, Inc.). Student's t-test (paired or unpaired) was used to estimate the statistical differences between two groups, and one-way or two-way analysis of variance and Tukey's post hoc test were used for comparison of multiple groups. Spearman's correlation analysis was used to assess the correlation between miR-1271-5p and AQP5 expression. $\mathrm{P}<0.05$ was considered to indicate a statistically significant difference.

\section{Results}

miR-1271-5p is downregulated, while AQP5 is upregulated, in HBV-HCC tissues. To determine the abundance of miR-1271-5p and AQP5 in HBV-HCC tissues, RT-qPCR analysis was performed to analyze their expression. The expression of miR-1271-5p was significantly lower in HBV-HCC tissues compared with that in adjacent normal tissues (Fig. 1A), while the expression of AQP5 mRNA was enhanced in HBV-HCC tissues (Fig. 1B). Correlation analysis revealed a negative correlation between AQP5 and miR-1271-5p levels (Fig. 1C). The data suggested that 
A

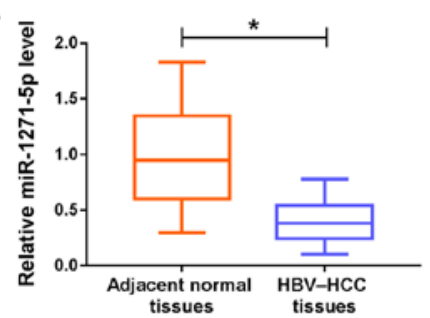

B

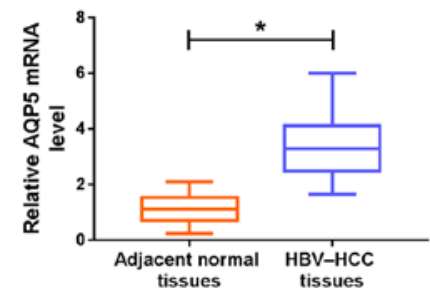

C

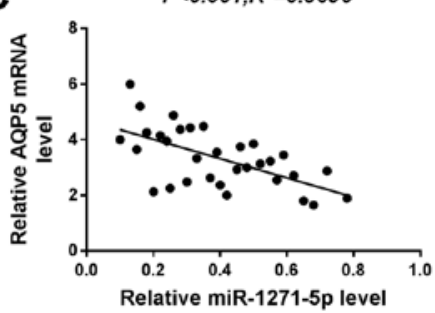

Figure 1. Expression of miR-1271-5p and AQP5. (A) The expression of miR-1271-5p in HBV-related HCC tissues and adjacent normal tissues was measured by RT-qPCR. (B) Expression of AQP5 at the mRNA level was also measured by RT-qPCR. (C) A negative correlation existed between the expression of miR-1271-5p and AQP5. "P<0.05. miR, microRNA; AQP5, aquaporin 5; HBV, hepatitis B virus; HCC, hepatocellular carcinoma; RT-qPCR, reverse transcription-quantitative PCR.

A
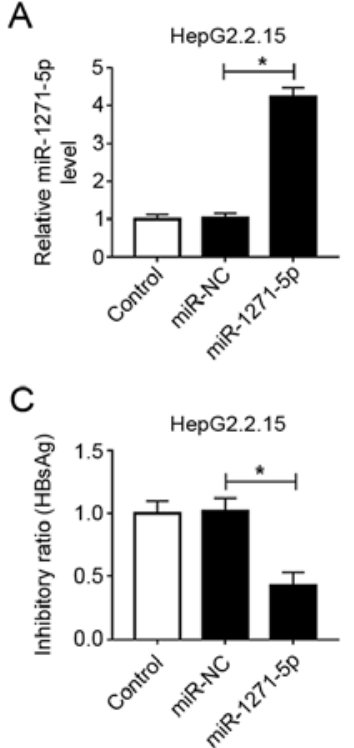
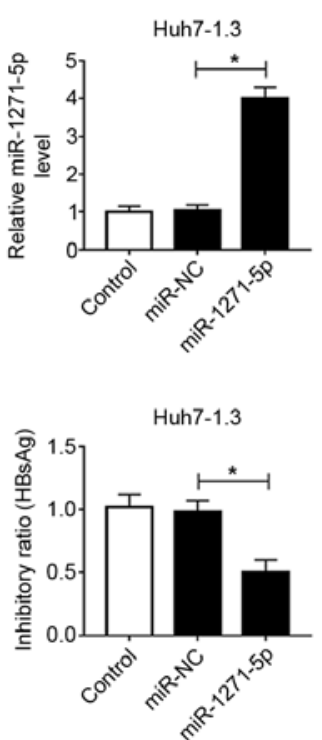

B
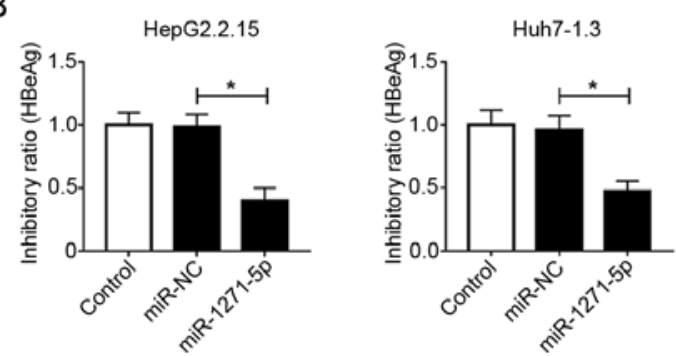

D
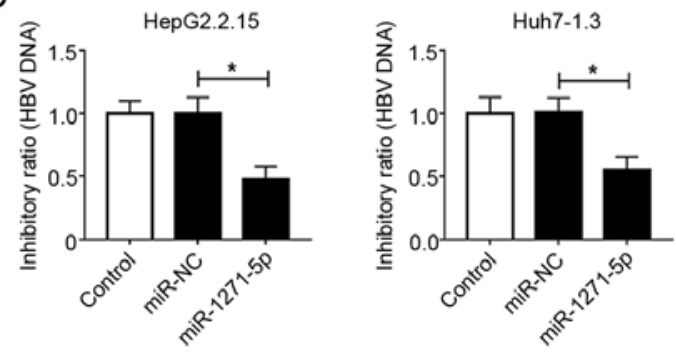

Figure 2. Effects of miR-1271-5p overexpression on the levels of HBeAg, HBsAg and HBV DNA. (A) The expression of miR-1271-5p in HepG2.2.15 and Huh7-1.3 transfected with miR-1271-5p mimic and miR-NC was measured by RT-qPCR. The levels of (B) HBeAg, (C) HBsAg and (D) HBV DNA were distinguished by ELISA or quantitative PCR. "P<0.05. miR, microRNA; NC, negative control; HBV, hepatitis B virus; RT-qPCR, reverse transcription-quantitative PCR; HBeAg, hepatitis B e-antigen; HBsAg, hepatitis B surface antigen.

miR-1271-5p and AQP5 may serve important roles, at least in part, in HBV-associated HCC.

Overexpression of miR-1271-5p inhibits the infection and replication of $H B V$ in $H B V$-related liver cancer cells. To examine the influence of miR-1271-5p on HBV infection, analyses of antigen secretions and HBV replication were performed. First, the efficiency of miR-1271-5p overexpression, as detected by RT-qPCR, demonstrated that the abundance of miR-1271-5p was increased in both HepG2.2.15 and Huh7-1.3 cells with miR-1271-5p mimic transfection (Fig. 2A). ELISA analysis revealed that the levels of HBeAg and HBsAg declined with the increase in miR-1271-5p compared with those in the miR-NC group (Fig. 2B and C). In addition, the level of HBV DNA was also notably reduced in HepG2.2.15 and Huh7-1.3 cells transfected with miR-1271-5p mimic compared with that of miR-NC-transfected cells (Fig. 2D). These data indicated that miR-1271-5p enrichment contributed to alleviating HBV infection by inhibiting the secretion of $\mathrm{HBeAg}$ and $\mathrm{HBsAg}$ and the replication of HBV.
Overexpression of miR-1271-5p blocks viability, migration and invasion, but induces apoptosis, in HBV-related liver cancer cells. To explore the role of miR-1271-5p on the progress of HBV-associated liver cancer, CCK-8, flow cytometry and Transwell assays were performed on cancer cells. Cell viability was markedly reduced by miR-1271-5p transfection both in HepG2.2.15 and Huh7-1.3 cells compared with that of miR-NC-transfected cells (Fig. 3A). By contrast, the number of apoptotic cells was clearly increased with the accumulation of miR-1271-5p (Fig. 3B). Several apoptosis-related proteins were analyzed by western blotting, which demonstrated that the levels of Bax and cleaved-caspase-3 were enhanced, while the Bcl-2 level decreased in HepG2.2.15 and Huh7-1.3 cells transfected with miR-1271-5p compared with that in cells transfected with miR-NC (Fig. 3C and D). The number of migrated and invaded cells was less in HepG2.2.15 and Huh7-1.3 cells transfected with miR-1271-5p compared with that of miR-NC-transfected cells (Fig. 3E and F). These data revealed that overexpression of miR-1271-5p positively reduced the malignant behaviors of $\mathrm{HBV}$-associated liver cancer in vitro. 
A
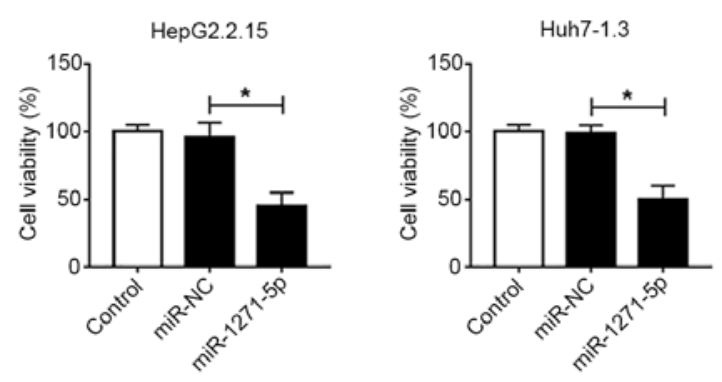

B

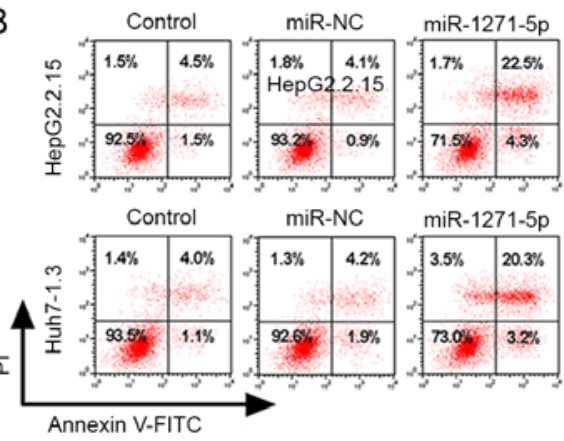

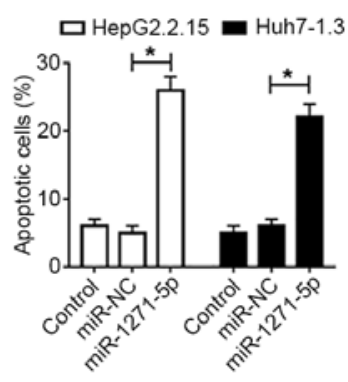

C
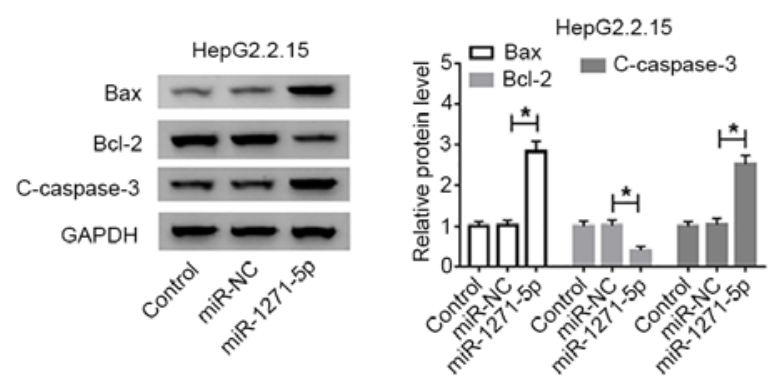

D

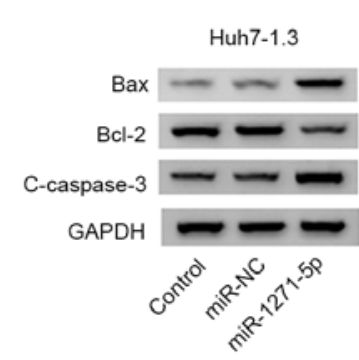

Huh7-1.3

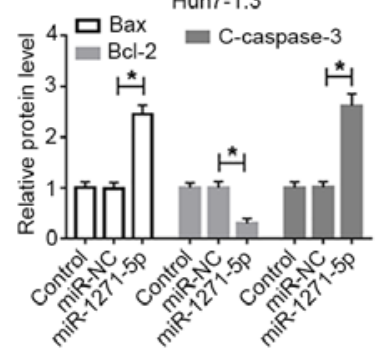

$E$

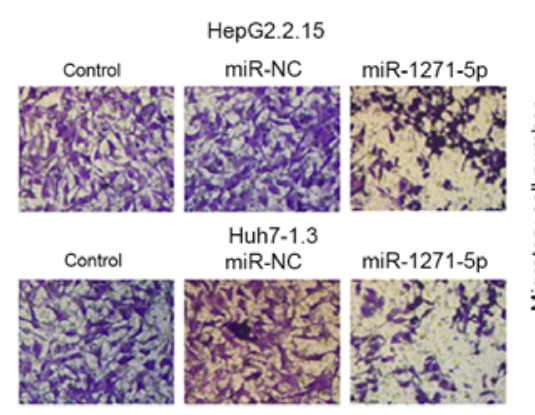

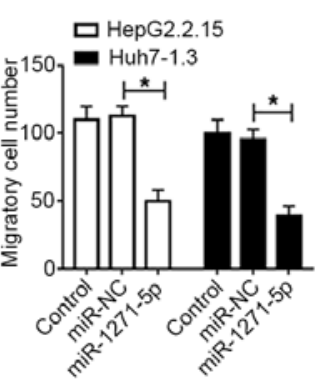

$\mathrm{F}$

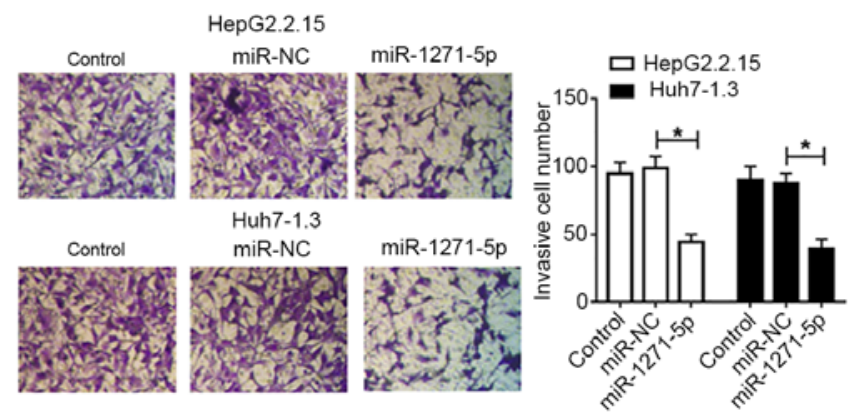

Figure 3. Effects of miR-1271-5p overexpression on cell viability, apoptosis, migration and invasion. (A) Cell viability was detected by Cell Counting Kit- 8 assay. (B) Cell apoptosis was assessed by flow cytometry. Apoptosis-related proteins, including Bax, Bcl-2 and cleaved-caspase-3, were quantified by western blotting in (C) HepG2.2.15 and (D) Huh7-1.3 cells. Transwell assay was performed to monitor cell (E) migration and (F) invasion (magnification, x100). ${ }^{*} \mathrm{P}<0.05$. miR, microRNA; NC, negative control; C-caspase-3, cleaved-caspase-3.

AQP5 knockdown reduces the levels of HBeAg, HBsAg and $H B V D N A$, inhibits viability, migration and invasion, and promotes apoptosis in cancer cells. To investigate the role of AQP5 in the progress of HBV-associated liver cancer, the expression level of AQP5 was knocked down in cancer cells. The AQP5 protein level was decreased in HepG2.2.15 and Huh7-1.3 cells transfected with si-AQP5 compared that in the scramble group (Fig. 4A). ELISA suggested that the levels of $\mathrm{HBeAg}$ and HBsAg were impaired with the lack of AQP5 in both HepG2.2.15 and Huh7-1.3 cells (Fig. 4B and C). Similarly, the level of HBV DNA was reduced in cells transfected with si-AQP5 (Fig. 4D). CCK-8 assay revealed that si-AQP5 efficiently impeded the viability of HepG2.2.15 and Huh7-1.3 cells (Fig. 4E). Flow cytometry revealed that si-AQP5 increased the number of apoptotic cells (Fig. 4F). The protein levels of Bax and cleaved-caspase-3 were enhanced, while the Bcl-2 level was depleted, with the decrease in AQP5 in both HepG2.2.15 and Huh7-1.3 cells (Fig. 4G and H). Transwell assay demonstrated that the number of migrated and invaded cells was decreased in HepG2.2.15 and Huh7-1.3 cells transfected with si-AQP5 compared with that in the scramble group (Fig. $4 \mathrm{I}$ and J). The above data demonstrated that AQP5 knockdown attenuated malignant behaviors of $\mathrm{HBV}$-associated liver cancer in vitro.

$A Q P 5$ is a target of $m i R-1271-5 p$. To understand the interaction of AQP5 with miR-1271-5p, the putative binding sites between them were predicted using the bioinformatics tool TargetScan. The sequences of AQP5-wt 3' UTR and AQP5-mut 3' UTR containing miR-1271-5p binding site or mutated binding site are shown in Fig. 5A. Dual-luciferase reporter assay demonstrated that the luciferase activity was considerably reduced in HepG2.2.15 and Huh7-1.3 cells co-transfected with AQP5-wt and $\mathrm{miR}-1271-5 \mathrm{p}$, whereas the no significant difference in luciferase activity was observed in the AQP5-mut group compared with that of the miR-NC group (Fig. 5B). The expression levels of miR-1271-5p were significantly decreased in HepG2.2.15 and Huh7-1.3 cells transfected with anti-miR-1271-5p 
A

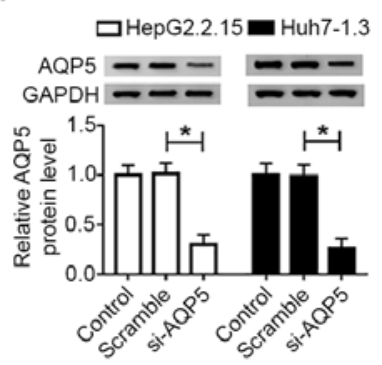

E

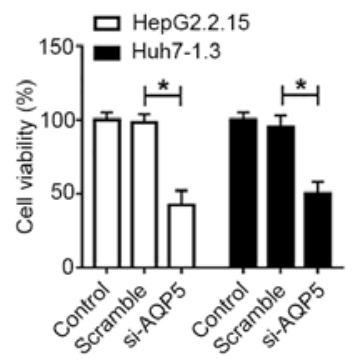

$\mathrm{H}$

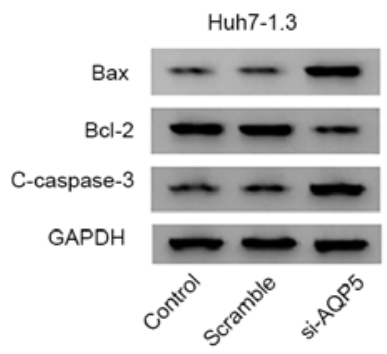

B

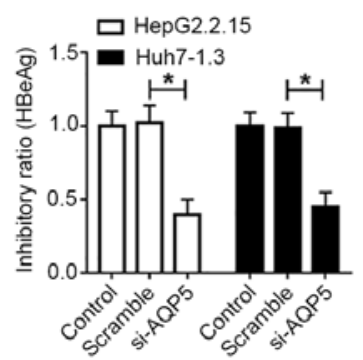

$\mathrm{F}$

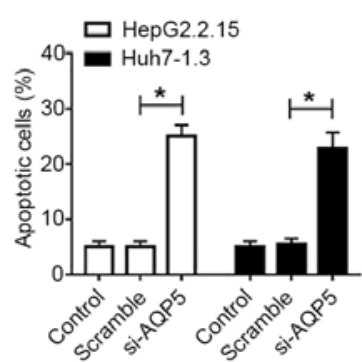

।

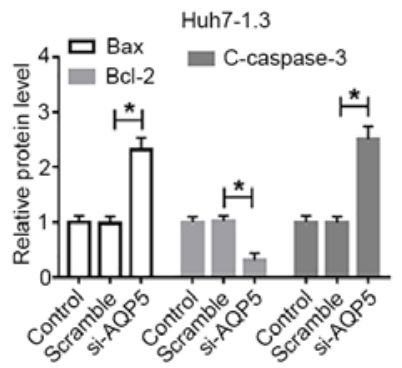

C

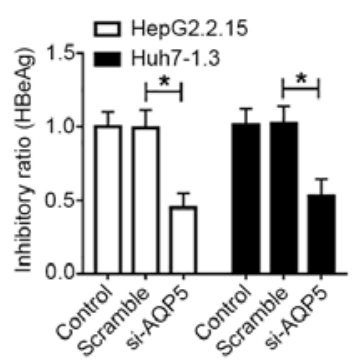

G
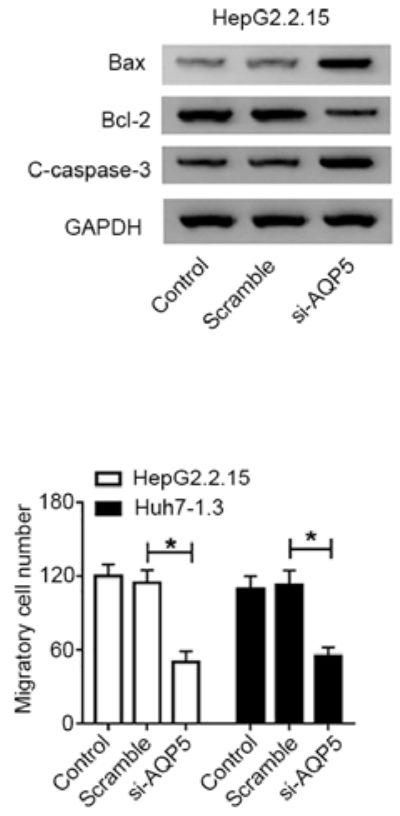

$J$

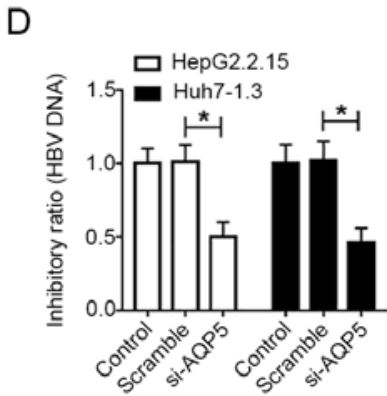

HepG2.2.15
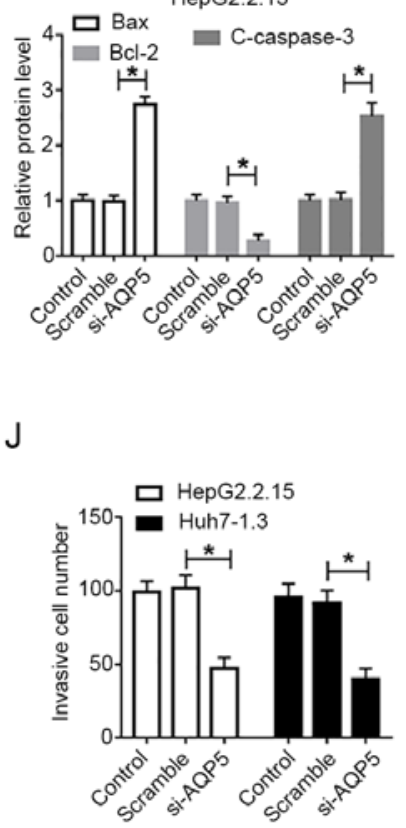

Figure 4. Effects of AQP5 knockdown on the levels of HBeAg, HBsAg and HBV DNA, cell viability, apoptosis, migration and invasion. (A) The expression of AQP5 in HepG2.2.15 and Huh7-1.3 cells transfected with si-AQP5 or scramble was measured by western blotting. The levels of (B) HBeAg, (C) HBsAg and (D) HBV DNA were assessed by ELISA or quantitative PCR. (E) Cell viability was detected by Cell Counting Kit-8 assay. (F) Cell apoptosis was assessed by flow cytometry. Bax, Bcl-2 and cleaved-caspase-3 were quantified by western blotting in (G) HepG2.2.15 and (H) Huh7-1.3 cells. Transwell assay verified cell (I) migration and (J) invasion. * $\mathrm{P}<0.05$. AQP5, aquaporin 5; HBV, hepatitis B virus; si, small interference.

compared with anti-miR-NC (Fig. 5C). By contrast, the inhibition of miR-1271-5p had the opposite effects to miR-1271-5p mimic on luciferase activity in HepG2.2.15 and Huh7-1.3 cells (Fig. 5D). Additionally, RIP assay indicated that miR-1271-5p clearly reinforced the enrichment of AQP5 in the RIP-Ago2 group compared with that in the RIP-lgG group in HepG2.2.15 and Huh7-1.3 cells (Fig. 5E). The protein level of AQP5 was depleted by miR-1271-5p but stimulated by anti-miR-1271-5p compared with their corresponding controls in HepG2.2.15 and Huh7-1.3 cells (Fig. 5F). These data implied that AQP5 was a direct target of miR-1271-5p and that its expression level was regulated by miR-1271-5p.

Overexpression of $A Q P 5$ reverses the effects of miR-1271-5p mimic in HBV-associated liver cancer cells. To investigate the mechanism of miR-1271-5p in the progress of HBV-mediated liver cancer, miR-1271-5p and miR-1271-5p + AQP5 together with their corresponding controls miR-NC and miR-1271-5p + vector were transfected into HepG2.2.15 and Huh7-1.3 cells. The detection of AQP5 overexpression efficiency demonstrated that
AQP5 was overexpressed, since the expression of AQP5 was significantly increased in HepG2.2.15 and Huh7-1.3 cells transfected with AQP5 compared with that of cells transfected with vector (Fig. S1). The data from western blotting demonstrated that miR-1271-5p + AQP5 transfection recovered the protein level of AQP5 that was weakened by miR-1271-5p transfection (Fig. 6A), suggesting that the transfection had been effective. ELISA established that the levels of HBeAg and HBsAg suppressed by miR-1271-5p mimic were significantly restored with the increase in AQP5 expression (Fig. 6B and C). Similarly, the level of HBV DNA was decreased by miR-1271-5p mimic but increased by AQP5 overexpression (Fig. 6D). In addition, miR-1271-5p + AQP5 transfection reversed the inhibitory effect of miR-1271-5p on cell viability (Fig. 6E). By contrast, the apoptosis induced by miR-1271-5p was alleviated with AQP5 overexpression (Fig. 6F). Western blot analysis demonstrated that the levels of Bax and cleaved-caspase-3 were enhanced by miR-1271-5p but reduced by AQP5 upregulation, while the level of Bcl-2 was impaired by miR-1271-5p but improved by AQP5 overexpression in HepG2.2.15 and Huh7-1.3 cells (Fig. 6G and H). 
A

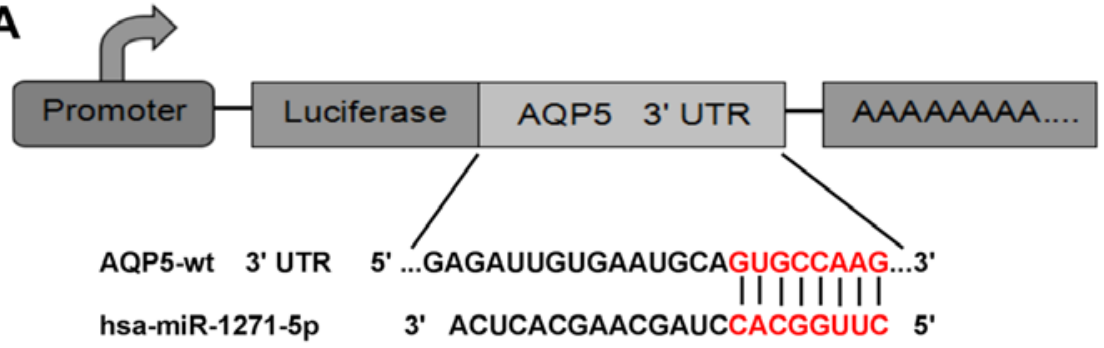

B
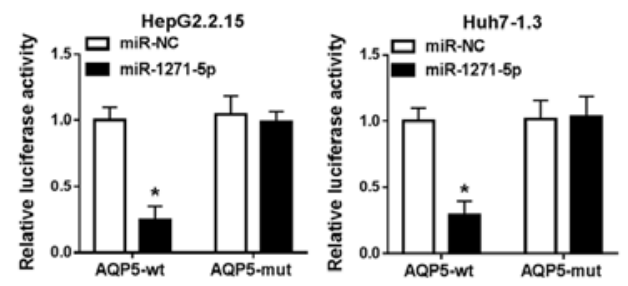

C

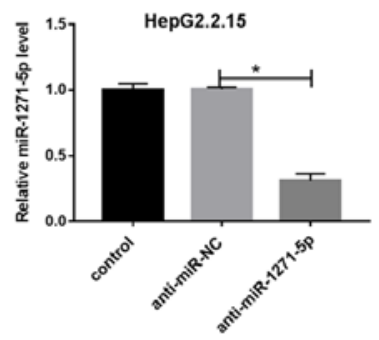

E

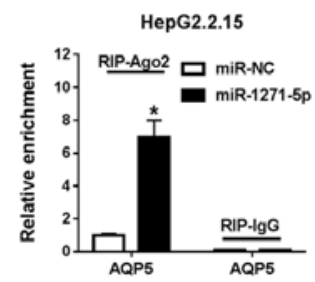

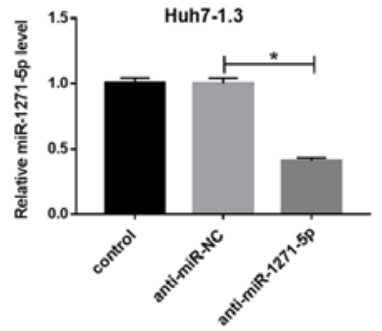

D

F

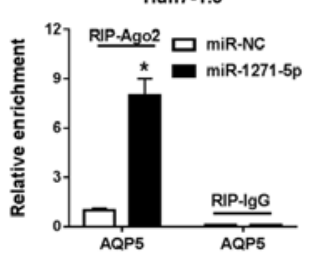

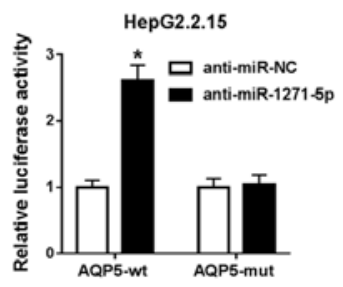
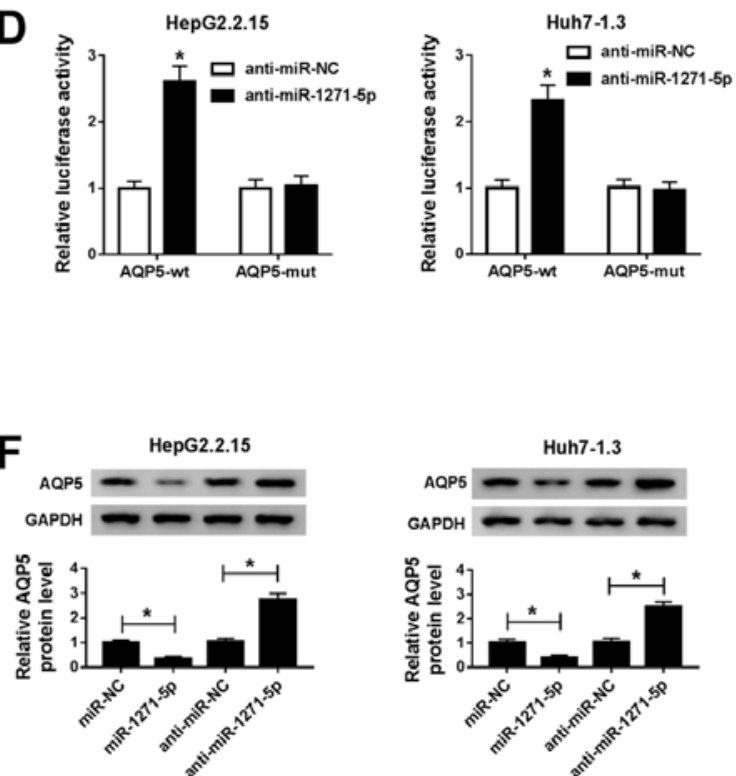

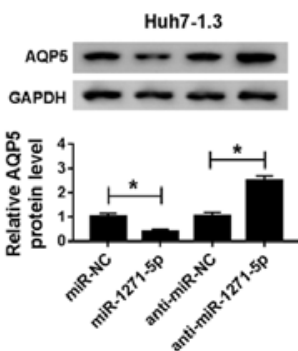

Figure 5. AQP5 is a target of miR-1271-5p. (A) The bioinformatics tool TargetScan was used to analyze the binding sites between miR-1271-5p and AQP5 3 UTR. (B) Dual-luciferase reporter assay was used to verify the association between them. (C) Efficiency of miR-1271-5p inhibitor was assessed via RT-qPCR. (D) Dual-luciferase reporter assay was performed in cells transfected with AQP5-wt or AQP5-mut and anti-miR-1271-5p or anti-miR-NC. (E) RIP assay was performed to further confirm the association. (F) Influence of miR-1271-5p overexpression or knockdown on the expression of AQP5 at the protein level. * $\mathrm{P}<0.05$. AQP5, aquaporin 5; miR, microRNA; UTR, untranslated region; wt, wild-type; mut, mutant; NC, negative control; RIP, RNA binding protein immunoprecipitation.

Transwell assay demonstrated that miR-1271-5p + AQP5 transfection reinforced the number of migratory or invasive cells reduced by miR-1271-5p transfection (Fig. 6I and J). Overall, these data demonstrated that miR-1271-5p blocked the malignant behaviors of HBV-associated liver cancer by suppressing the expression of AQP5.

Overexpression of miR-1271-5p obstructs tumor growth in vivo. To further validate the function of miR-1271-5p on tumor growth in vivo, a nude mouse tumorigenicity assay was performed. HepG2.2.15 cells transfected with miR-1271-5p or miR-NC were subcutaneously injected into the nude mice. The results demonstrated that tumor volume was lower in the miR-1271-5p group compared with that in the miR-NC group from week 1 until the mice were sacrificed (Fig. 7A). Tumor weight was also lower in the miR-1271-5p group compared with that in the miR-NC group, and the largest tumor diameters observed were 7.4 and $13.5 \mathrm{~mm}$ in the miR-1271-5p and miR-NC groups, respectively (Fig. 7B). Expression analysis revealed that the level of miR-1271-5p was enhanced in tumor tissues from the miR-1271-5p group, while the protein level of AQP5 decreased in the miR-1271-5p group compared with that of the miR-NC group (Fig. 7C and D). miR-1271-5p overexpression also increased the level of an apoptosis-related protein, cleaved-caspase-3, while decreasing the level of a cell cycle-related protein, PCNA, compared with the findings in the miR-NC group (Fig. 7E). The data from ELISA demonstrated that the levels of $\mathrm{HBeAg}$ and $\mathrm{HBsAg}$ were reduced in the miR-1271-5p group compared with those in the miR-NC group (Fig. 7F). Additionally, the level of HBV DNA was also significantly impaired in the miR-1271-5p group compared with that in the miR-NC group (Fig. 7G). Taken together, these data demonstrated that miR-1271-5p overexpression could inhibit tumor growth in vivo.

\section{Discussion}

HBV is a primary causative agent of chronic liver diseases, which is difficult to cure because integrated virus templates-induced proteins easily initiate and accelerate chronic liver diseases (17). Identifying potential gene targets in the pathogenesis of HBV infection may provide opportunities for the development of specific therapies to combat liver cancer. In the present study, low expression of miR-1271-5p and 
A

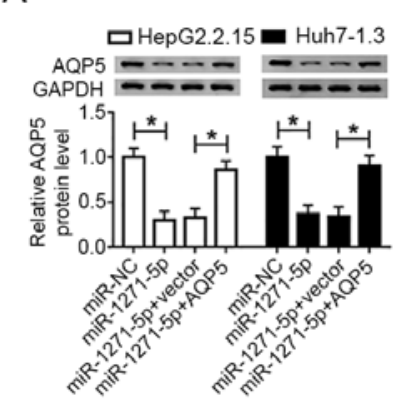

$E$

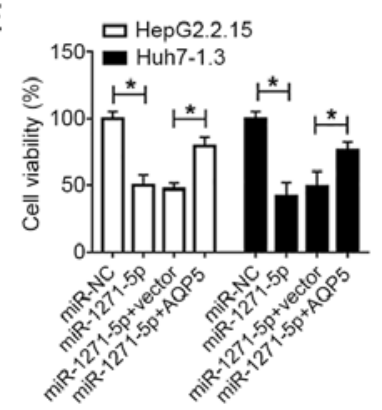

$\mathrm{H}$

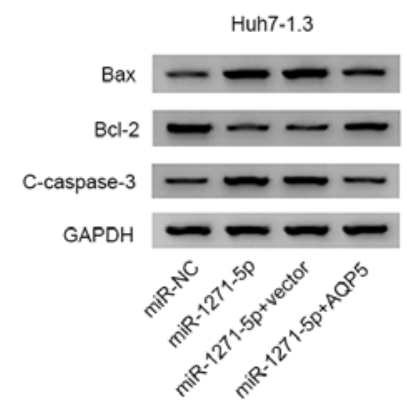

B

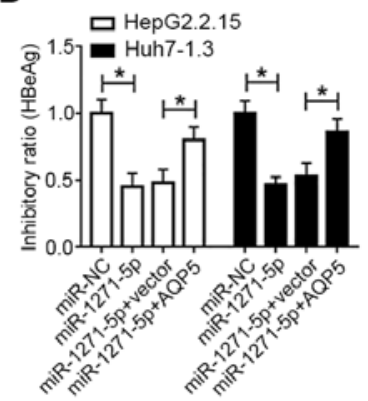

$\mathrm{F}$

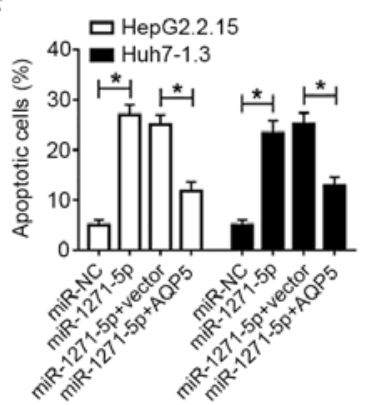

1

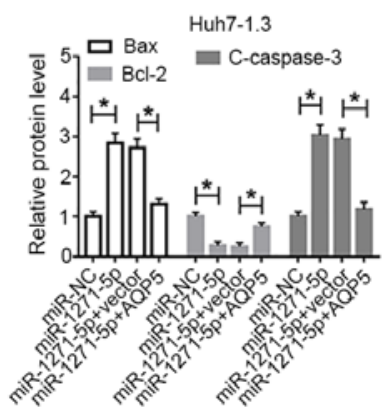

C

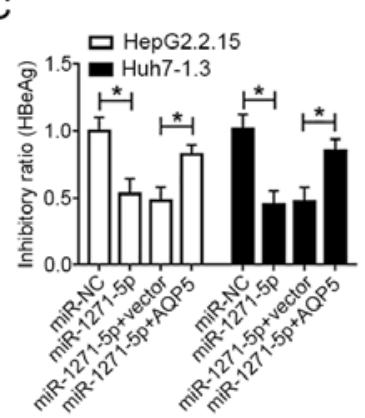

D

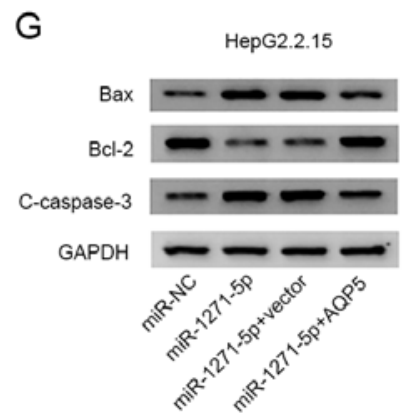

$J$

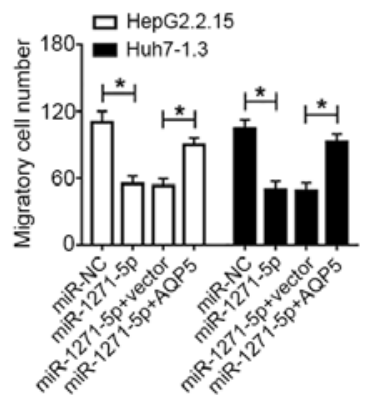

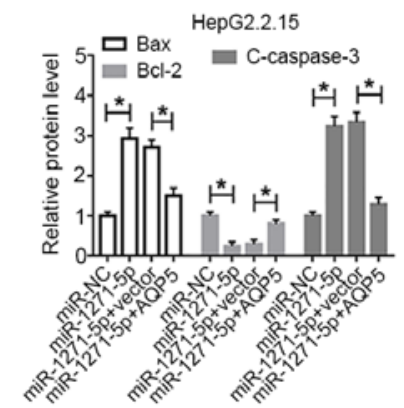

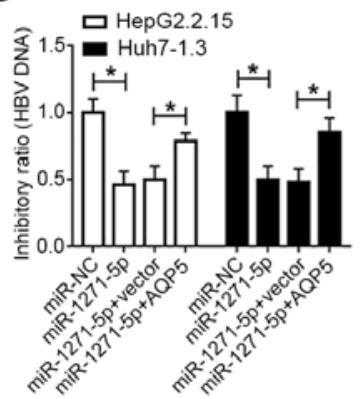

HepG2.2.15

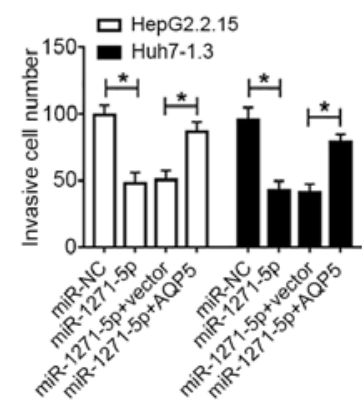

Figure 6. miR-1271-5p regulates the levels of HBeAg, HBsAg and HBV DNA, as well as cell viability, apoptosis, migration and invasion, by binding to AQP5. HepG2.2.15 and Huh7-1.3 cells were transfected with miR-1271-5p, miR-NC, miR-1271-5p + AQP5 or miR-1271-5p + vector. (A) The protein level of AQP5 was detected by western blotting. (B) HBeAg, (C) HBsAg and (D) HBV DNA levels were detected by ELISA or quantitative PCR. (E) Cell viability was assessed by Cell Counting Kit-8 assay. (F) Apoptosis was examined by flow cytometry. Bax, Bcl-2 and cleaved-caspase-3 were quantified by western blotting in (G) HepG2.2.15 and (H) Huh7-1.3 cells. (I) Migration and (J) invasion were determined by Transwell assay. "P<0.05. miR, microRNA; HBV, hepatitis B virus; AQP5, aquaporin 5; NC, negative control; C-caspase-3, cleaved-caspase-3.

high expression of AQP5 were detected in HBV-related liver cancer tissues and cells. Functional analyses disclosed that miR-1271-5p overexpression inhibited the levels of $\mathrm{HBeAg}$, HBsAg and HBV DNA, as well the cell viability, migration and invasion, but promoted cell apoptosis. AQP5 knockdown exerted a similar function with miR-1271-5p overexpression. In addition, miR-1271-5p regulated HBV infection and liver cancer development via competitively targeting AQP5. Nude mouse tumorigenicity assay strengthened the hypothesis that miR-1271-5p impeded tumor growth in vivo.

Various studies have suggested that miR-1271-5p can suppress cell proliferation and metastasis in different types of cancer, such as endometrial cancer (18), glioblastoma (19), gastric cancer (20) and HCC (21-23). Notably, a previous study observed that miR-1271-5p exhibits relatively low expression in HBV-associated HCC tissues, and its upregulation impairs HBV-DNA replication, proliferation and metastasis by promoting the adenosine monophosphate-activated protein kinase (AMPK) signaling pathway (24). Another study stated that miR-1271-5p can reduce cell growth and migration by binding to forkhead box K2 in HCC (10). Consistent with these data, the present study observed lower expression of miR-1271-5p in HBV-associated liver cancer tissues and cells, and its reintroduction effectively reduced HBV-DNA replication, $\mathrm{HBeAg}$ and $\mathrm{HBsAg}$ levels, cell viability and metastasis. Thus, the function of miR-1271-5p in HBV-associated liver cancer might be related to tumor inhibition.

In the present study, AQP5 was confirmed as a target of miR-1271-5p. AQP5, which is $21-24 \mathrm{kDa}$ in molecular weight, is regarded as the main structural caveolae protein from cell membranes (25). Satisfactory progress has been made in the research on AQP5 in HCC. He et al (26) concluded that AQP5 is highly expressed in HCC cells, and its inhibition blocks $\mathrm{HCC}$ metastasis and EMT by regulating the NF- $\mathrm{KB}$ signaling pathway. Zhang et al (25) noted that the expression of AQP5 is accumulated in HBV-HCC tissues and cells, and that AQP5 
A

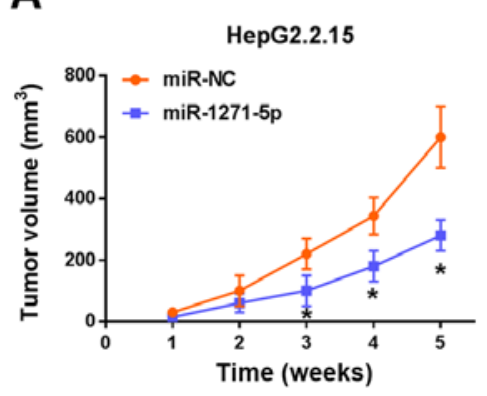

B

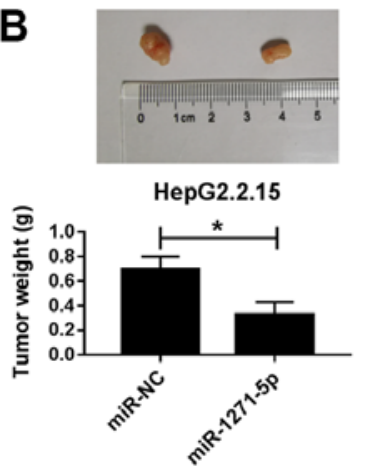

E
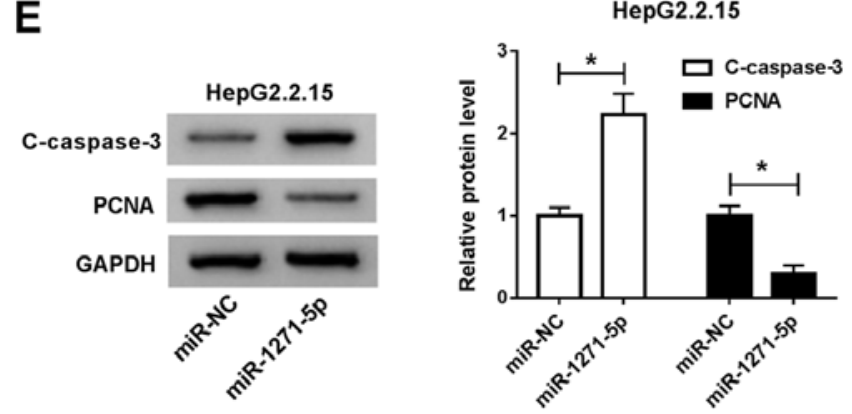

C

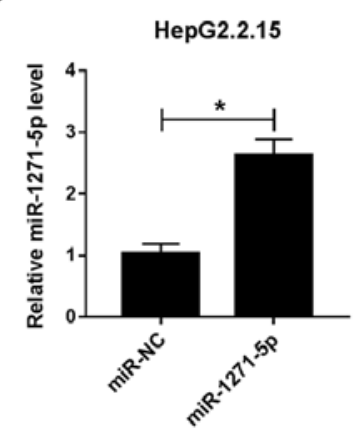

F

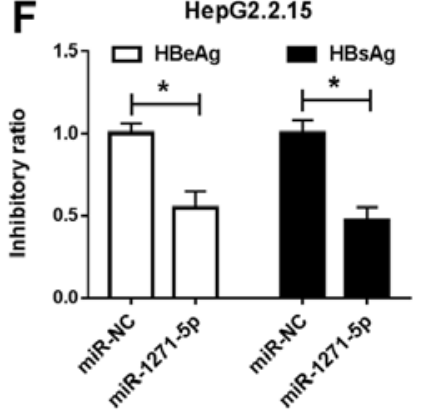

D

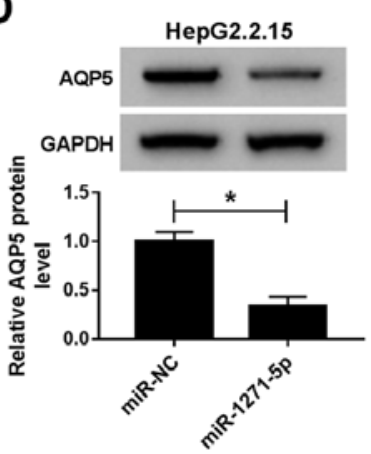

G

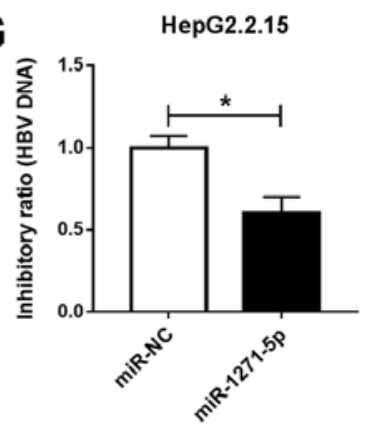

Figure 7. Effect of miR-1271-5p overexpression on tumor growth in vivo. (A) Tumor volume was recorded once a week. (B) Tumor weight after 5 weeks. (C) Expression of miR-1271-5p in tumor tissues was measured by reverse transcription-quantitative PCR. (D) Expression of AQP5 at the protein level in tumor tissues was determined by western blotting. (E) Cleaved-caspase-3 and PCNA were quantified by western blotting. (F) Levels of HBeAg and HBsAg were assessed by ELISA. (G) The level of HBV DNA was examined using quantitative PCR. * $\mathrm{P}<0.05$. miR, microRNA; AQP5, aquaporin 5; PCNA, proliferating cell nuclear antigen; HBV, hepatitis B virus; NC, negative control; C-caspase-3, cleaved-caspase-3.

contributes to cell proliferation but reduces apoptosis. In agreement with these previous studies, the present study observed that a high level of AQP5 was present in HBV-associated liver cancer tissues and cells. AQP5 interference helped to ameliorate the extent of HBV infection and malignant activities of tumor cells, suggesting that AQP5 possessed carcinogenesis effects, at least in liver cancer.

$\mathrm{HBsAg}$ is a sensitive and specific biomarker of HBV infection. The detection of HBsAg is the primary diagnostic tool for the diagnosis, prevention and treatment of HBV (27). $\mathrm{HBeAg}$ is an indicator of HBV replication, and its high abundance indicates that $\mathrm{HBV}$ replication is active and that the viral load is high (28). Generally, the level of HBV DNA is an indicator to measure the replication of HBV (29). Therefore, the levels of HBsAg, HBeAg and HBV DNA have been used in previous studies to measure HBV infection (30-32). For example, miR-125a-5p overexpression can inhibit the secretion of HBsAg and $\mathrm{HBeAg}$, but does not change the replication of HBV DNA (30). Long non-coding RNA highly upregulated in liver cancer enhances the levels of HBsAg, HBeAg and cccDNA, and activates HBV replication in HBV-infected cells (31). miR-302c-3p protects against HBV replication by reducing the concentrations of $\mathrm{HBV}$ DNA and $\mathrm{HBsAg}$ in HBV transgenic mice (32). Similarly, in the present study, miR-1271-5p mimic or AQP5 knockdown could reduce the levels of $\mathrm{HBsAg}, \mathrm{HBeAg}$ and HBV DNA, indicating that miR-1271-5p functioned on blocking HBV replication, while AQP5 exhibited the opposite effect.

Collectively, the data from the present study concluded that miR-1271-5p inhibited cell viability, migration and invasion, induced apoptosis, attenuated HBV infection in vitro, and impeded tumor growth in vivo by targeting AQP5. Thus, miR-1271-5p may be a promising biomarker for therapy of $\mathrm{HBV}$-associated liver cancer.

\section{Acknowledgements}

Not applicable.

\section{Funding}

No funding was received.

\section{Availability of data and materials}

The datasets used and/or analyzed during the current study are available from the corresponding author on reasonable request.

\section{Authors' contributions}

ZL conceived and designed the experiments, which were performed by LM and LD. ZL and XL analyzed the data and wrote the manuscript. All authors read and approved the final manuscript.

\section{Ethics approval and consent to participate}

The present study was approved by the Ethics Committee of The Second Affiliated Hospital of Shandong First Medical 
University. Each patient signed the informed consent form. The animal experiments were approved by the Institutional Animal Care and Use Committee of The Second Affiliated Hospital of Shandong First Medical University.

\section{Patient consent for publication}

Not applicable.

\section{Competing interests}

The authors declare that they have no competing interests.

\section{References}

1. De Giorgio M and Fagiuoli S: Management of hepatocellular carcinoma. Dig Dis 25: 279-281, 2007.

2. Ferlay J, Shin HR, Bray F, Forman D, Mathers C and Parkin DM: Estimates of worldwide burden of cancer in 2008: GLOBOCAN 2008. Int J Cancer 127: 2893-2917, 2010.

3. El-Serag HB and Rudolph KL: Hepatocellular carcinoma: Epidemiology and molecular carcinogenesis. Gastroenterology 132: 2557-2576, 2007.

4. Amir F, Siddiqui ZI, Farooqui SR, Anwer A, Khan S, Azmi MI, Mehmankhah M, Dohare R, Khan LA and Kazim SN: Impact of length of replication competent genome of hepatitis B virus over the differential antigenic secretion. J Cell Biochem 120: 17858-17871, 2019.

5. Downs LO, Smith DA, Lumley SF, Patel M, Mcnaughton AL, Mokaya J, Ansari MA, Salih H, Varnai KA, Freeman O, et al: Electronic health informatics data to describe clearance dynamics of hepatitis B surface antigen ( $\mathrm{HBsAg}$ ) and e antigen $(\mathrm{HBeAg})$ in chronic hepatitis B virus infection. MBio 10: e00699-19, 2019.

6. Gu S, Jin L, Zhang F, Sarnow P and Kay MA: Biological basis for restriction of microRNA targets to the $3^{\prime}$ untranslated region in mammalian mRNAs. Nat Struct Mol Biol 16: 144-150, 2009.

7. Bai PS, Xia N, Sun H and Kong Y: Pleiotrophin, a target of miR-384, promotes proliferation, metastasis and lipogenesis in HBV-related hepatocellular carcinoma. J Cell Mol Med 21: 3023-3043, 2017

8. Huang JY, Chen HL and Shih C: MicroRNA miR-204 and miR-1236 inhibit hepatitis B virus replication via two different mechanisms. Sci Rep 6: 34740, 2016.

9. Yen CS, Su ZR, Lee YP, Liu IT and Yen CJ: miR-106b promotes cancer progression in hepatitis B virus-associated hepatocellular carcinoma. World J Gastroenterol 22: 5183-5192, 2016.

10. Lin MF, Yang YF, Peng ZP, Zhang MF, Liang JY, Chen W, Liu XH and Zheng YL: FOXK2, regulted by miR-1271-5p, promotes cell growth and indicates unfavorable prognosis in hepatocellular carcinoma. Int J Biochem Cell Biol 88: 155-161, 2017.

11. Direito I, Madeira A, Brito MA and Soveral G: Aquaporin-5: From structure to function and dysfunction in cancer. Cell Mol Life Sci 73: 1623-1640, 2016.

12. Sekine S, Shimada Y, Nagata T, Moriyama M, Omura T, Watanabe T, Hori R, Yoshioka I, Okumura T, Sawada S, et al: Prognostic significance of aquaporins in human biliary tract carcinoma. Oncol Rep 27: 1741-1747, 2012

13. Song T, Yang H, Ho JC, Tang SC, Sze SC, Lao L, Wang Y and Zhang KY: Expression of aquaporin 5 in primary carcinoma and lymph node metastatic carcinoma of non-small cell lung cancer. Oncol Lett 9: 2799-2804, 2015.

14. Zhang L, Lu J, Zhou H, Du Z and Zhang G: Silencing of aquaporin 5 inhibits the growth of A549 lung cancer cells in vitro and in vivo. Int J Oncol 52: 1643-1650, 2018.

15. Jung HJ, Park JY, Jeon HS and Kwon TH: Aquaporin-5: A marker protein for proliferation and migration of human breast cancer cells. PLoS One 6: e28492, 2011.
16. Livak KJ and Schmittgen TD: Analysis of relative gene expression data using real-time quantitative PCR and the 2(-Delta Delta C(T)) method. Methods 25: 402-408, 2001.

17. Arzumanyan A, Reis HM and Feitelson MA: Pathogenic mechanisms in HBV- and HCV-associated hepatocellular carcinoma. Nat Rev Cancer 13: 123-135, 2013.

18. Tian Y, Chen YY and Han AL: MiR-1271 inhibits cell proliferation and metastasis by targeting LDHA in endometrial cancer. Eur Rev Med Pharmacol Sci 23: 5648-5656, 2019.

19. Yang L, Wang Y, Li YJ and Zeng CC: Chemo-resistance of A172 glioblastoma cells is controlled by miR-1271-regulated Bcl-2. Biomed Pharmacother 108: 734-740, 2018.

20. Lim B, Kim HJ, Heo H, Huh N, Baek SJ, Kim JH, Bae DH, Seo EH, Lee SI, Song KS, et al: Epigenetic silencing of miR-1271 enhances MEK1 and TEAD4 expression in gastric cancer. Cancer Med 7: 3411-3424, 2018 (Epub ahead of print).

21. Li C, Jiang Y, Miao R, Qu K, Zhang J and Liu C: MicroRNA-1271 functions as a metastasis and epithelial-mesenchymal transition inhibitor in human HCC by targeting the PTP4A1/c-Src axis. Int J Oncol 52: 536-546, 2018.

22. Qin A, Zhu J, Liu X, Zeng D, Gu M and Lv C: MicroRNA-1271 inhibits cellular proliferation of hepatocellular carcinoma. Oncol Lett 14: 6783-6788, 2017.

23. Maurel M, Jalvy S, Ladeiro Y, Combe C, Vachet L, Sagliocco F, Bioulac-Sage P, Pitard V, Jacquemin-Sablon H, Zucman-Rossi J, et al: A functional screening identifies five microRNAs controlling glypican-3: Role of miR-1271 down-regulation in hepatocellular carcinoma. Hepatology 57: 195-204, 2013.

24. Chen Y, Zhao ZX, Huang F, Yuan XW, Deng L and Tang D: MicroRNA-1271 functions as a potential tumor suppressor in hepatitis B virus-associated hepatocellular carcinoma through the AMPK signaling pathway by binding to CCNA1. J Cell Physiol 234: 3555-3569, 2019.

25. Zhang Z, Han Y,Sun G, Liu X, Jia X and Yu X: MicroRNA-325-3p inhibits cell proliferation and induces apoptosis in hepatitis $\mathrm{B}$ virus-related hepatocellular carcinoma by down-regulation of aquaporin 5. Cell Mol Biol Lett 24: 13, 2019.

26. He Z, Dong W, Hu J and Ren X: AQP5 promotes hepatocellular carcinoma metastasis via NF- $\kappa \mathrm{B}$-regulated epithelial-mesenchymal transition. Biochem Biophys Res Commun 490: 343-348, 2017.

27. Hadziyannis E and Laras A: Viral biomarkers in chronic $\mathrm{HBeAg}$ negative HBV infection. Genes (Basel) 9: 469, 2018.

28. Kam W, Rall LB, Smuckler EA, Schmid R and Rutter WJ: Hepatitis B viral DNA in liver and serum of asymptomatic carriers. Proc Natl Acad Sci USA 79: 7522-7526, 1982.

29. Hc Y and Jh K: Persistence of hepatitis B virus covalently closed circular DNA in hepatocytes: Molecular mechanisms and clinical significance. Emerg Microbes Infect 3: e64, 2014.

30. Li G, Zhang W, Gong L and Huang X: MicroRNA 125a-5p inhibits cell proliferation and induces apoptosis in hepatitis B virus-related hepatocellular carcinoma by downregulation of ErbB3. Oncol Res 27: 449-458, 2019.

31. Liu Y, Feng J, Sun M, Yang G, Yuan H, Wang Y, Bu Y, Zhao M, Zhang $S$ and Zhang X: Long non-coding RNA HULC activates HBV by modulating HBx/STAT3/miR-539/APOBEC3B signaling in HBV-related hepatocellular carcinoma. Cancer Lett 454: 158-170, 2019.

32. Hamada-Tsutsumi S, Naito Y, Sato S, Takaoka A, Kawashima K, Isogawa M, Ochiya T and Tanaka Y: The antiviral effects of human microRNA miR-302c-3p against hepatitis B virus infection. Aliment Pharmacol Ther 49: 1060-1070, 2019.

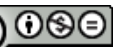

This work is licensed under a Creative Commons Attribution-NonCommercial-NoDerivatives 4.0 International (CC BY-NC-ND 4.0) License. 